\title{
Dysmyelination of Auditory Afferent Axons Increases the Jitter of Action Potential Timing during High-Frequency Firing
}

\author{
Jun Hee Kim, ${ }^{1}$ Robert Renden, ${ }^{2}$ and Henrique von Gersdorff ${ }^{2}$ \\ ${ }^{1}$ The Department of Physiology, University of Texas Health Science Center, San Antonio, Texas 78229 and ${ }^{2}$ The Vollum Institute, Oregon Health and \\ Science University, Portland, Oregon 97239
}

\begin{abstract}
Auditory neuropathies are linked to loss of temporal acuity of sound-evoked signals, which may be related to myelin loss. However, it is not known how myelin loss affects the waveform and temporal precision of action potentials (APs) in auditory CNS nerve terminals. Here we investigated the excitability of the calyx of Held nerve terminal in dysmyelinated auditory brainstems using the Long-Evans Shaker $(L E S)$ rat, a spontaneous mutant where compact myelin wrapping does not occur due to a genetic deletion of myelin basic protein. We found at relatively mature postnatal ages (15-17 d after birth) $L E S$ rat calyces showed prolonged spike latencies, indicative of a threefold reduction in the AP propagation velocity. Furthermore, LES rat afferent fiber-evoked APs showed a pronounced loss of temporal precision, even at low stimulation frequencies $(10 \mathrm{~Hz})$. While normal calyces were able to fire APs without failures at impressive rates of up to $1 \mathrm{kHz}$, LES calyces were unable to do so. Direct recordings of the presynaptic calyx terminal AP waveform revealed that myelin loss does not affect the AP spike upstroke and downstroke kinetics, but dysmyelination reduces the after-depolarization and enhances the fast after-hyperpolarization peak following the AP spike in the LES rat. Together these findings show that proper myelination is essential not only for fast AP propagation, but also for precise presynaptic AP firing that minimizes both spike jitter and failures, two characteristics critically important for the accurate processing of sound signals in the auditory brainstem.
\end{abstract}

\section{Introduction}

Axon diameter, degree of myelination, and the distance between nodes of Ranvier are all important parameters that determine action potential (AP) velocity (Seidl et al., 2010). Myelin reduces the effective membrane capacitance of axons, and thereby serves to speed up AP propagation (Barrett and Barrett, 1982). Accordingly, during postnatal development an increase in compact myelin is paralleled by a 10 -fold increase in AP conduction velocity at rat sciatic nerves (Vabnick and Shrager, 1998).

The calyx of Held synapse is part of the ascending auditory pathway that uses submillisecond differences in the timing of binaural signals to compute sound source localization (Carr et al., 2001). At this auditory brainstem synapse previous reports have shown that $\mathrm{AP}$ waveform and timing following axonal stimulation changes dur-

Received July 12, 2012; revised April 11, 2013; accepted April 18, 2013.

Author contributions: J.H.K., R.R., and H.v.G. designed research; J.H.K. and R.R. performed research; J.H.K., R.R., and H.v.G. analyzed data; J.H.K., R.R., and H.v.G. wrote the paper.

This work was supported by National Institute on Deafness and Other Communication Disorders Grants R03 DC011140 (J.H.K.) and R01 DC012938 (H.v.G.). We thank Drs. lan Duncan and Jacek M. Kwiecien for providing the initial LES rat breeding pairs and for tips on how to care for the rats and breed them. We thank Drs. T. Kuner (University of Heidelberg) and C. Kushmerick (Federal University of Minas Gerais, Brazil) for valuable discussions.

Correspondence should be addressed to either of the following: Dr. Jun Hee Kim, Department of Physiology, University of Texas Health Science Center, San Antonio, TX 78229, E-mail: kimjh@uthscsa.edu; or Dr. Henrique von Gersdorff, The Vollum Institute, Oregon Health and Science University, 3181 SW Sam Jackson Park Road, Portland, OR 97239, E-mail: vongersd@ohsu.edu.

R. Renden's present address: Department of Psychology and Department of Biology, University of Nevada, Reno, 1664 North Virginia Street, Reno, NV 89557

DOI:10.1523/JNEUROSCI.3389-12.2013

Copyright $\odot 2013$ the authors $\quad 0270-6474 / 13 / 339402-06 \$ 15.00 / 0$ ing early postnatal development (Taschenberger and von Gersdorff, 2000; Leão et al., 2005), perhaps due in part to increased myelination. However, the role of axonal myelination on AP waveform and presynaptic excitability has not been directly tested at CNS boutontype nerve terminals due to their small size.

Here, we studied the effect of dysmyelination on AP propagation speed, fidelity of timing, and reliability of spiking during low- and high-frequency firing at the large calyx of Held terminal using the Long-Evans Shaker $(L E S)$ rat. This spontaneous mutant has a severe dysmyelinating phenotype and completely lacks compact myelin in the adult CNS, due to a retroviral genetic lesion that specifically disrupts expression of myelin basic protein (MBP; Kwiecien et al., 1998; O'Connor et al., 1999). Behaviorally, the homozygous LES rat has severe shivering, locomotor deficits, and seizures, beginning at $\sim 2$ weeks after birth, although the animals are not deaf and can survive for up to 9 months with appropriate care (Smith et al., 2013). We characterized the deficits in AP propagation and reliability in the homozygous mutant and then compared these results to AP firing in normal heterozygous littermates, which showed no behavioral or morphological phenotype and were indistinguishable from wild type. Our findings help to explain how myelin loss can lead to hearing disabilities due to propagation delays and increased timing jitter in the AP transmission along the ascending mammalian auditory pathways (Oertel, 2005; Zeng et al., 2005).

\section{Materials and Methods}

Animals. LES rats (obtained from McMaster University, Canada) of either sex were used in accordance with approved Oregon Health and 
LE rat (P5)

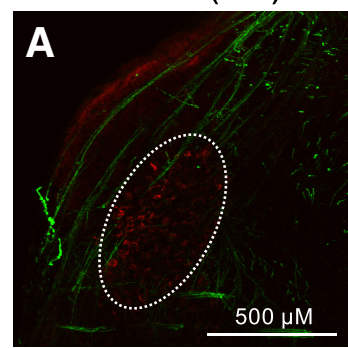

LE rat (P13)

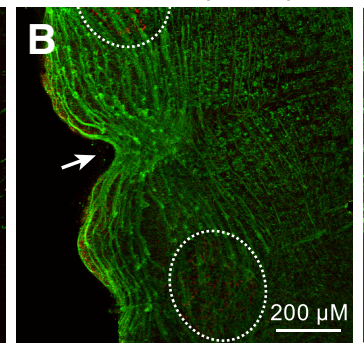

$L E$ rat $(\mathrm{P} 13)$

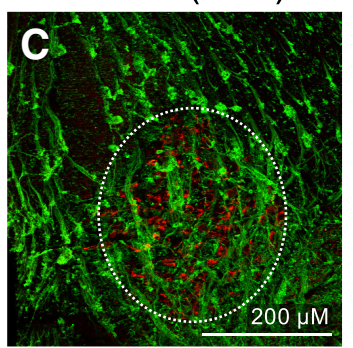

LE rat (P13)

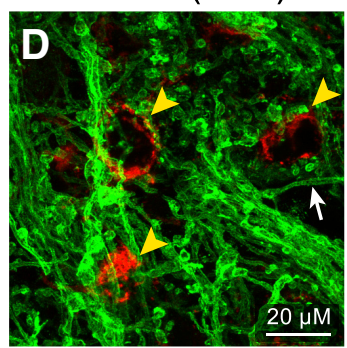

LES rat $(\mathrm{P} 17)$

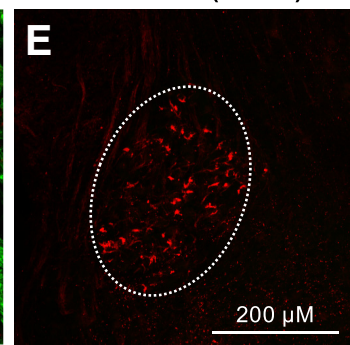

Figure 1. Expression of MBP in the rodent auditory brainstem increases with age. Fixed slices of auditory brainstem containing the ventral stria and MNTB were stained for myelin (MBP; green) and for synaptic vesicles (VGluT1; red). $\boldsymbol{A}$, In normal young rats (LE rat; P5), sparse myelin is present in axonal projections. $\boldsymbol{B}$, Soon after the onset of hearing (P13), myelin is highly expressed in MNTB axons, and terminates close to the calyx of Held presynaptic terminal. The arrow indicates the midline, where the bipolar stimulus electrode was placed. The areas containing the MNTB are indicated by dotted lines. $\boldsymbol{C}$, Enlarged image of $\boldsymbol{B}$, showing staining of presynaptic glutamatergic terminals and myelinated axons in the MNTB. $\boldsymbol{D}$, Enlarged image of $\boldsymbol{C}$, showing staining of presynaptic calyx-like terminals (yellow arrowheads) and myelinated axons in the MNTB. The white arrow shows a single isolated myelinated axon. $\boldsymbol{E}$, A P17 mutant $L E S$ rat completely lacks staining for MBP, but synaptic vesicle staining (VGluT1; red) in the MNTB appears to be normal.

Science University and University of Texas Health Science Center at San Antonio Institutional Animal Care and Use Committee protocols. Animals were maintained as heterozygotes, and crossed to generate pups homozygous for the MBP mutation. LES could be easily identified by gross movement disorders at 2 weeks following birth (Delaney et al., 1995). Heterozygous or wild-type littermates (normal $L E$ ) showed no abnormalities in behavior, and were used as controls. The breeding of heterozygous pups for obtaining homozygous (LES rat) pups was difficult due to the long breeding interval ( $\sim 3$ months) and the extended care that the mutant rats required to stay healthy.

Slice preparation. Transverse brainstem slices (200 $\mu \mathrm{m}$ thick) were prepared from $L E$ and $L E S$ rat pups of postnatal day 15-18 (P15-P18). After rapid decapitation, the brainstem was removed from the skull and immersed in ice-cold artificial CSF (aCSF) for slicing containing the following (in mM): $125 \mathrm{NaCl}, 2.5 \mathrm{KCl}, 3 \mathrm{MgCl}_{2}, 0.1 \mathrm{CaCl}_{2}, 25$ glucose, 25 $\mathrm{NaHCO}_{3}, 1.25 \mathrm{NaH}_{2} \mathrm{PO}_{4}, 0.4$ ascorbic acid, 3 myo-inositol, and $2 \mathrm{Na}-$ pyruvate, $\mathrm{pH}$ 7.3-7.4, when bubbled with carbogen $\left(95 \% \mathrm{O}_{2}, 5 \% \mathrm{CO}_{2}\right.$; osmolality of 310-320 mOsm). After cutting the slices were transferred to an incubation chamber containing normal aCSF bubbled with carbogen and maintained at $35^{\circ} \mathrm{C}$ for $30 \mathrm{~min}$, and thereafter at room temperature. Normal aCSF was the same as slicing aCSF, but with $1 \mathrm{~mm} \mathrm{MgCl}_{2}$ and $2 \mathrm{mM} \mathrm{CaCl}_{2}$.

Electrophysiology. Whole-cell patch-clamp recordings were performed in normal aCSF at room temperature $\left(22-24^{\circ} \mathrm{C}\right.$ ) or $35^{\circ} \mathrm{C}$ (see Fig. $4 \mathrm{C}$ ). Pipette solution contained the following (in $\mathrm{mm}$ ): $130 \mathrm{~K}$-gluconate, 20 $\mathrm{KCl}, 5 \mathrm{Na}$-phosphocreatine, 10 HEPES, $4 \mathrm{Mg}$-ATP, 5 mM EGTA, and $0.3 \mathrm{GTP}, \mathrm{pH}$ adjusted to 7.3 with $\mathrm{KOH}$. Presynaptic APs were recorded using the fast current-clamp mode of the EPC-10 amplifier (HEKA). Current-clamp recordings were continued only if initial uncompensated series resistance $R_{s}<20 \mathrm{M} \Omega$. Membrane potentials were not corrected for a calculated liquid junction potential of $11 \mathrm{mV}$. Presynaptic APs were elicited with a bipolar electrode and an Iso-Flex (A.M.P.I.) stimulator delivered $100 \mu$ s pulses $<15 \mathrm{~V}$. Data were acquired at $20-100 \mathrm{kHz}$ and filtered on-line at $2.9 \mathrm{kHz}$. Differences were considered statistically significant when $p<0.05$ by Student's $t$ test.

Immunohistochemistry. Brainstem slices $(150-200 \mu \mathrm{m})$ were fixed with $4 \%(\mathrm{w} / \mathrm{v})$ paraformaldehyde in PBS for $60 \mathrm{~min}$. Free-floating sections were permeabilized 30 min with $0.5 \%$ Triton X-100. For staining, slices were blocked in $0.3 \%$ goat serum in PBS and incubated overnight at $4^{\circ} \mathrm{C}$ with mouse monoclonal anti-myelin basic protein (1:4000; Sternberger Monoclonals), or monoclonal guinea pig anti-vesicular glutamate transporter 1 (VGluT1) antibody (1:1000, Millipore Bioscience Research Reagents). Staining was reported by incubation with appropriate Alexa dye-conjugated secondary antibodies for $2 \mathrm{~h}$ at room temperature. Slices were mounted onto SuperFrost slides in photobleaching-protective medium. Stained slices were viewed with laser lines at 488 and $633 \mathrm{~nm}$ using a $60 \times$ oil-immersion objective on a confocal laser-scanning microscope (Olympus FluoView 300).

\section{Results}

Myelin loss significantly reduced AP firing precision

In normal $L E$ rat brain slices, we detected the presence of myelin in the ventral striatum of the auditory brainstem, projecting to the medial nucleus of the trapezoid body (MNTB), using an antibody for MBP (Fig. 1, green). Axons innervating the immature MNTB (P5-P6) showed sparse staining for $\operatorname{MBP}(n=7$; Fig. $1 A)$. However, myelin was highly expressed in MNTB axons soon after the onset of hearing at P13 ( $n=7$; Fig. $1 B$, green). Myelin terminated near the calyces of Held (stained red with antibody for VGluT1; Fig. 1C,D), but was excluded from the $20-50 \mu \mathrm{m}$ heminode region of the preterminal axon (Leão et al., 2005). Brainstem slices from $L E S$ rats showed similar expression of VGluT1 as the control, but no staining for MBP (Fig. $1 E$ ). This suggests that the calyx synapse formation and morphology in LES rats is not grossly disturbed by the MBP mutation.

To test the effect of myelin loss on the timing of presynaptic APs, we examined presynaptic spikes using noninvasive cellattached recordings and also in whole-cell patch-clamp recordings of APs from normal rats ( $L E$; control) and in dysmyelinated axons from $L E S$ rats $(L E S)$. The AP spike recorded in the calyx is initiated at the distal axon near the tip of the bipolar stimulation electrode in the brainstem midline and then propagates to the calyx terminal (Paradiso and $\mathrm{Wu}, 2009$ ). Both cell-attached and whole-cell recordings from normal calyx terminals at P16 revealed that presynaptic spike timing is very precise and reliable; however, the $L E S$ rats showed pronounced timing errors of presynaptic APs. In LES, we observed increased AP latency and increased temporal jitter at $10 \mathrm{~Hz}$ stimulation, even at nearly 3 weeks after birth (Fig. 2). We compared the conduction velocity in presynaptic terminals from normal myelinated axons with dysmyelinated axons by measuring spike latency in noninvasive cell-attached recordings and AP latency in whole-cell recordings, as the time delay from the stimulation artifact to the cell-attached spike or whole-cell AP peak, respectively. We placed the bipolar afferent fiber stimulator on the midline of auditory brainstem slices (Fig. $1 B$, arrow), which is $\sim 300-400 \mathrm{~mm}$ away from the MNTB. Remarkably, the mutant LES exhibited a nearly twofold longer spike latency $(1.27 \pm 0.15 \mathrm{~ms}$ vs $0.69 \pm 0.07 \mathrm{~ms}, n=7$ and 8 , respectively; Fig. $2 A$ ) between stimulus artifact and spike peaks in cell-attached recordings. In the same patch recordings, after achieving the whole-cell configuration, AP latency was $1.49 \pm$ $0.25 \mathrm{~ms}$ versus $0.52 \pm 0.06 \mathrm{~ms}$ (Fig. $2 B, C$ ), a nearly threefold 
change in latency. Given that the distance between the bipolar stimulating electrode and the locations of the patch recordings was $\sim 400-800 \mu \mathrm{m}$ (Fig. $1 B$ ), we estimate the AP conduction velocity in the axon was $\sim 0.8-1.5 \mathrm{~m} \cdot \mathrm{s}^{-1}$ in $L E$ rats at room temperature, and threefold slower in LES rats. Additionally, the temporal precision of the APs was degraded in LES rats (jitter range: $255 \pm 41 \mu$ s in $\mathrm{P} 16-\mathrm{P} 18$ LES rats vs $62 \pm 8 \mu \mathrm{s}$ in normal $L E$ rats, $p<0.001$, $n=5$; Fig. $2 C$ ). This increased jitter may be related to the slow AP speed in LES rats, which prolongs the delay time between spike initiation in the distal axon and spike arrival in the nerve terminal. Note that for long axons even small variations in AP speed will produce large differences in spike arrival times (Wang et al., 2008).

\section{Axonal myelination affects the waveform of the presynaptic APs}

We examined presynaptic AP waveforms in myelinated or dysmyelinated axon terminals from $L E$ and LES rats. There was no significant difference in AP amplitude (118 \pm 6.0 and $109 \pm 6.0 \mathrm{mV}$ in control and the LES, respectively, $n=5$ ) or half-width $(214 \pm 34.7$ and $183 \pm 64.3 \mathrm{~ms}$, respectively; cf. Fig. 2) at room temperature. Moreover, the average resting membrane potentials of $L E$ and $L E S$ calyces are not significantly different $(-79.8 \pm 0.6 \mathrm{mV}$ and $-78.5 \pm 0.8$ $\mathrm{mV}, n=6, p=0.2)$. A normal $L E$ rat at P15-P18 shows a large after-depolarization (ADP) with amplitude $11.4 \pm 3.0 \mathrm{mV}$ (from the peak of fast after-hyperpolarization (fAHP) to the peak of ADP) and decay time constant of $8.2 \pm 1.8 \mathrm{~ms}(n=5)$. These results are comparable to those in normal Sprague Dawley rats at P16 (13.8 $\pm 0.6 \mathrm{mV}$, $n=4$; Kim et al., 2010). However, P16-P18 LES rats displayed a smaller ADP $(7.8 \pm 1.3$ $\mathrm{mV}$ from the peak of fAHP to the peak of $\mathrm{ADP})$ with a fast decay $(9.2 \pm 2.1 \mathrm{~ms}, n=5$; Fig. 3A). Moreover, in LES rats the peak of the fAHP was more hyperpolarized $(-82.3 \pm 0.8 \mathrm{mV}$ vs $-77.8 \pm 1.5 \mathrm{mV}$ in control, $n=5, p<0.05$; Fig. $3 B$ ). Thus, the peak potential of the ADP measured from the resting membrane potential was significantly reduced to $3.9 \pm 0.9 \mathrm{mV}$ in $L E S$ rats from the normal $L E$ value of $11.5 \pm 2.2 \mathrm{mV}(n=6, p=0.014$; Fig. $3 C)$. Because a larger peak potential of the ADP facilitates the firing of subsequent spikes during a stimulus train (Fig. $4 B$, bottom superimposed traces; Kim et al., 2010), we suggest that a more hyperpolarized fAHP peak and smaller ADP in LES promotes a reduction in the reliability of repetitive firing at dysmyelinated MNTB axons.

\section{Axon myelination is critical for repetitive firing with high precision and fidelity}

We next examined the reliability of AP firing in dysmyelinated axons at high stimulation frequencies. Both normal LE and LES calyx terminals at P16-P17 can spike without failure at $100 \mathrm{~Hz}$

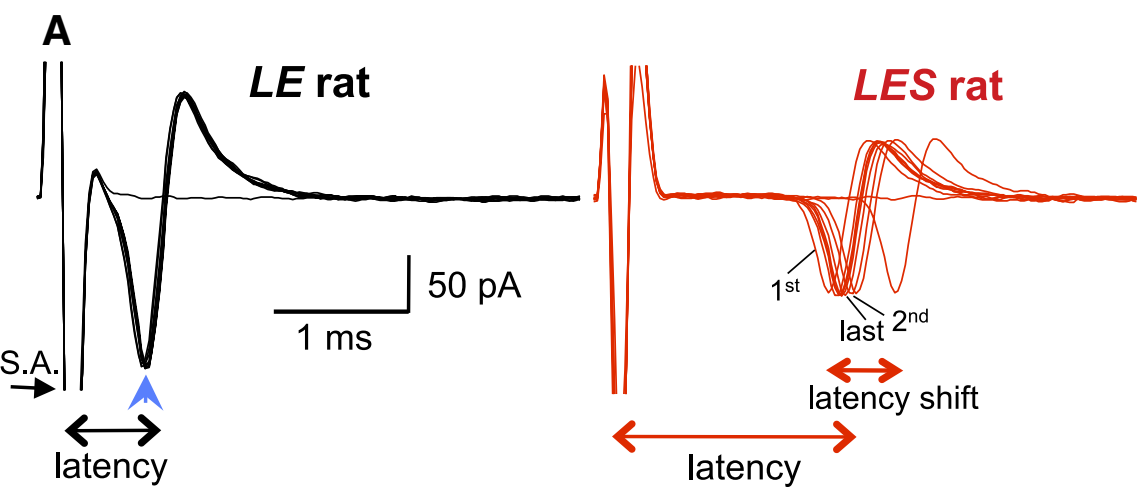

B

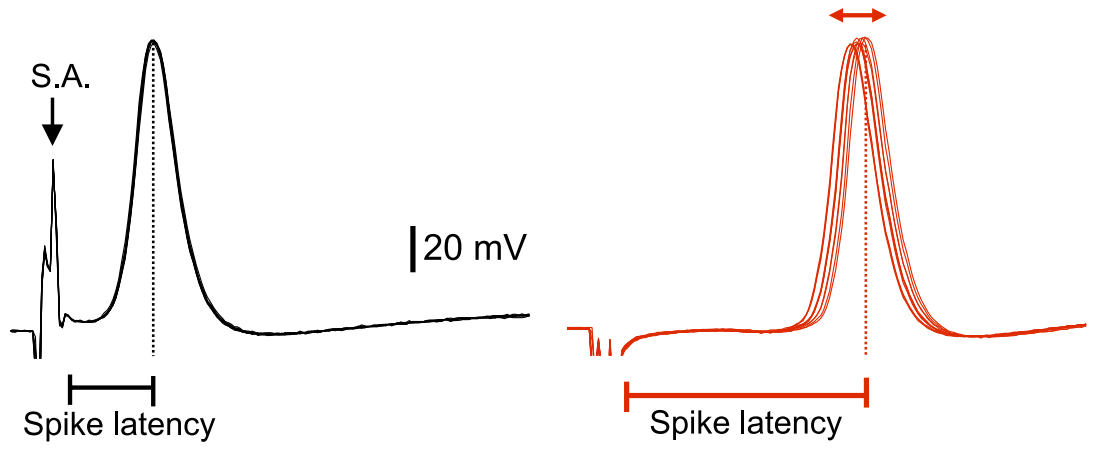

Spike jitter

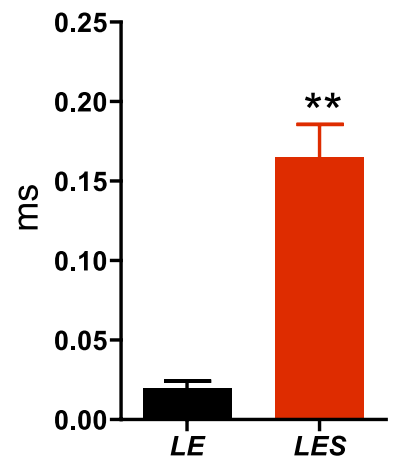

Figure 2. LES rats show increased presynaptic spike latency and a lack of temporal precision during $10 \mathrm{~Hz}$ repetitive firing. attached mode at a P17 calyx terminal: normal LE (black trace) and the LES mutant rat (red trace). Note the large latency shift (and temporal jitter) in the LES rat spikes (the labels first, second, and last indicate the order of responses to $10 \mathrm{~Hz}$ afferent fiber whole-cell current-clamp mode. Note the lack of precision (or jitter) in the timing of the spikes for LES mutants. C, Summary of the spike delay and jitter in $L E$ and $L E S$ rats $\left({ }^{* *} p<0.001\right)$. S.A., stimulus artifact.

(Fig. 4A). However, LES calyx terminals at P16-P17 showed intermittent AP failures during a stimulus train of $300 \mathrm{~Hz}$, while a normal calyx could fire spikes without failure at $300 \mathrm{~Hz}$ (Fig. $4 B$ ). In six of seven recordings from LES calyces at P16-P18, APs often failed to fire during $300 \mathrm{~Hz}$ AP trains (50 pulses). AP failures were intermittent, indicating that an AP triggering or propagation failure occurs along dysmyelinated axons. Increasing the stimulation intensity could not completely recover the failure of APs at dysmyelinated axons at $300 \mathrm{~Hz}$ stimulation (data not shown). In addition, raising the temperature of the bath solution from 24 to $37^{\circ} \mathrm{C}$ allowed the normal P16-P17 LE calyx terminals to fire APs without failures at $1 \mathrm{kHz}$ in normal calyces, but not at $L E S$ calyces (Fig. 4C). Our results indicate that loss of compact myelin reduces the reliability of spike firing at higher stimulation frequen- 
A

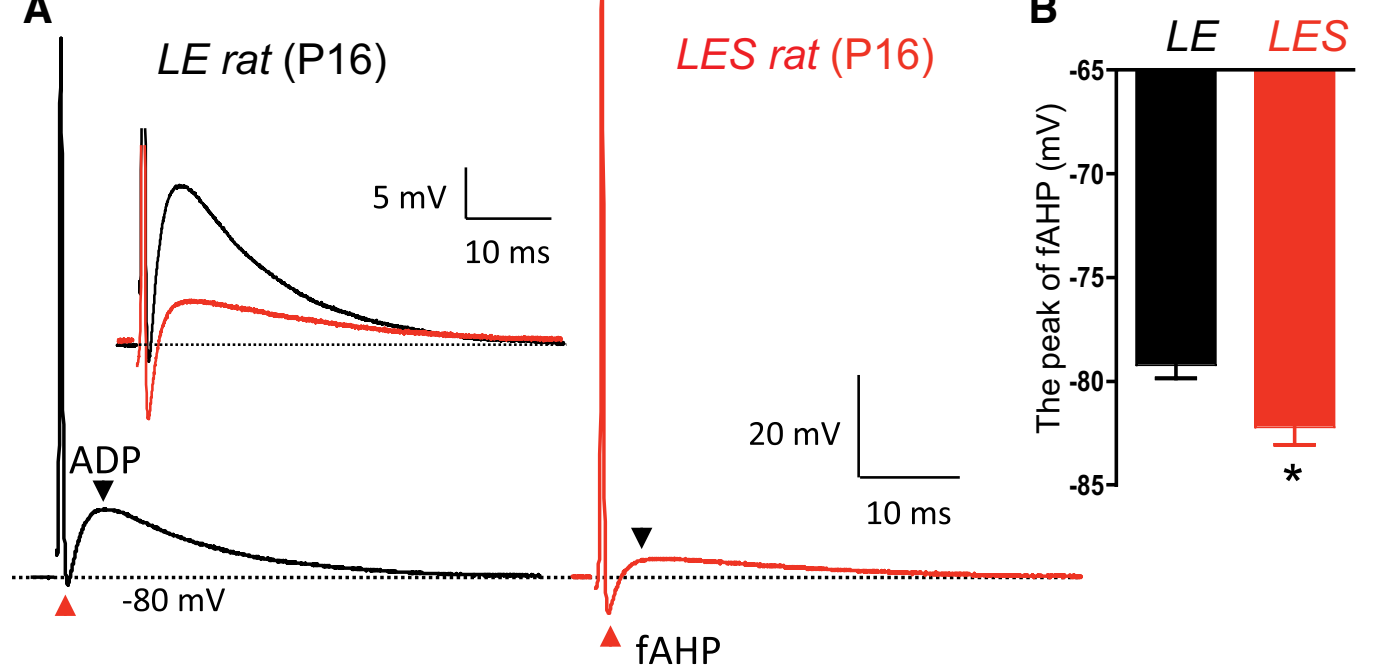

C

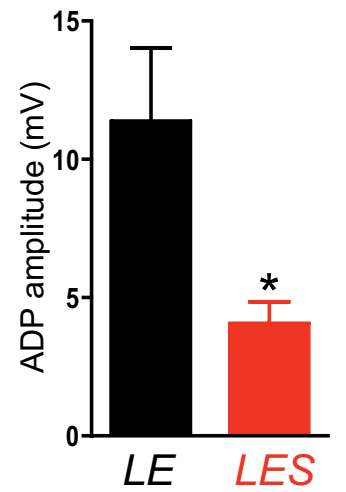

Figure 3. $L E S$ calyx terminals have a smaller ADP and an enhanced fAHP peak. Afferent fiber stimulation produced an action potential with an ADP in a P16 normal $L E$ calyx recording (black; $A$ ) and an ADP with a reduced peak value in a calyx from the LES (right, red trace). Both calyces displayed an ADP (black arrowhead) and fAHP (red arrowhead). Inset, Same traces on an expanded voltage scale. $B$, Peak reversal voltage of fAHP was significantly larger in calyces from LES than $L E$, recorded from P15-P18 rats. $\boldsymbol{C}$, Summary of the ADP amplitude, measured from resting potential to the peak of ADP in normal LE and mutant LES calyces in P15-P18 rats.
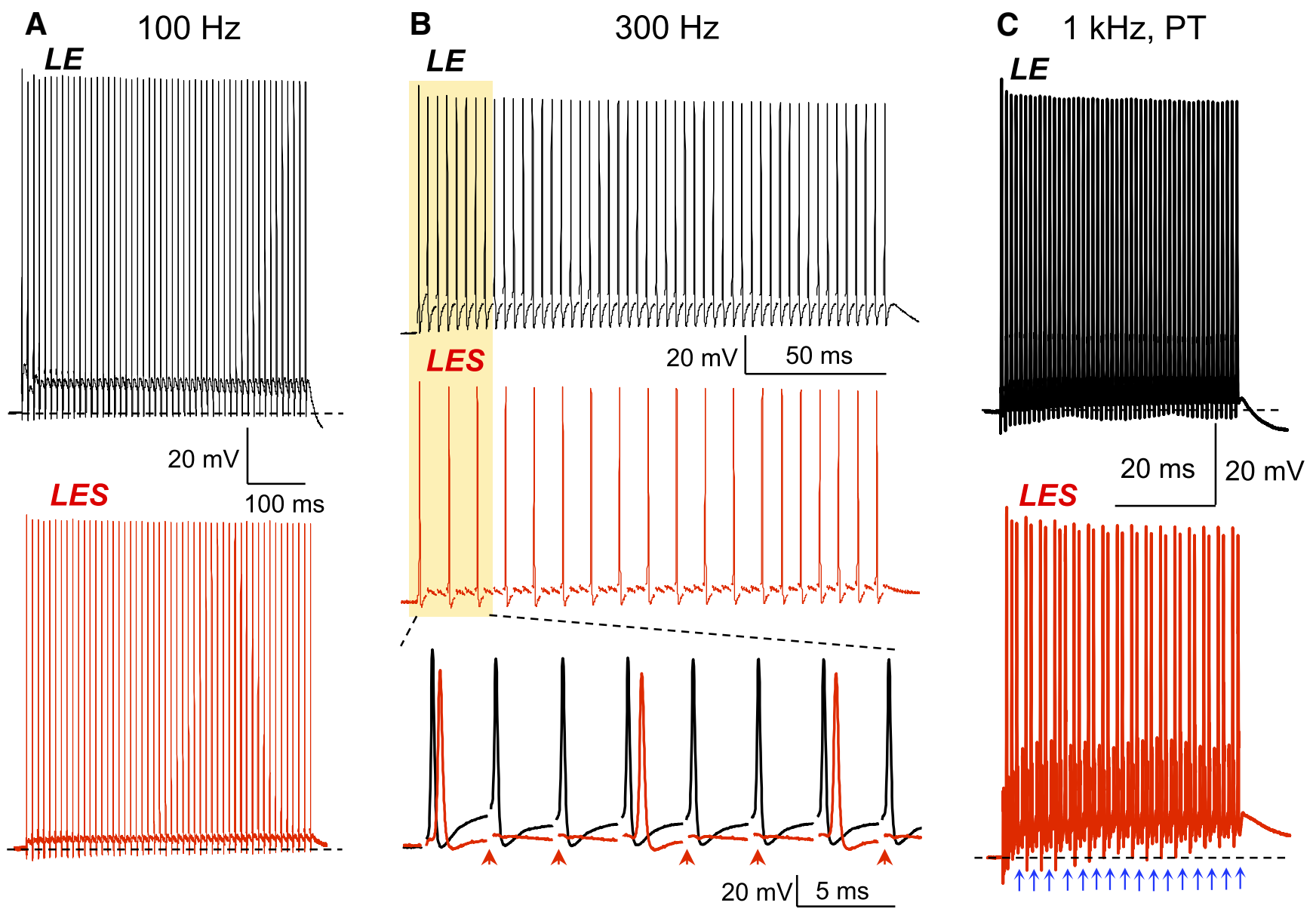

Figure 4. LES calyx terminals cannot follow APs at higher frequencies. AP trains were triggered at $100 \mathrm{~Hz}(\boldsymbol{A}), 300 \mathrm{~Hz}(\boldsymbol{B})$, and $1 \mathrm{kHz}(\boldsymbol{C})$ at room temperature $\left(24^{\circ} \mathrm{C}, \boldsymbol{A}\right.$ and $\left.\boldsymbol{B}\right)$ and at physiological temperature (PT; $37^{\circ} \mathrm{C}, \mathrm{C}$. The calyx of Held of both $L E$ and $L E S$ rats can follow $100 \mathrm{~Hz}$ stimulation, but at higher stimulation frequencies ( $300 \mathrm{~Hz}$ and $1 \mathrm{kHz}$ ) presynaptic $\mathrm{APs}$ of the $L E S$ calyx terminals experience intermittent failures, whereas normal $L E$ calyx terminals can routinely follow $300 \mathrm{~Hz}$ (at room temperature) and even $1 \mathrm{kHz}$ at $37^{\circ} \mathrm{C}$ without $\mathrm{AP}$ failures. Recordings were from $\mathrm{P} 16 \mathrm{LE}$ and LES rats (black and red traces, respectively). The horizontal dashed line indicates the resting membrane potential of $-80 \mathrm{mV}$. Arrowheads in $\boldsymbol{B}$ and blue arrows in $\boldsymbol{C}$ indicate AP failures. LES rats showed more AP failures and the timing of the APs showed more "jitter." 
cies. Thus, myelin is crucial for the ability of the calyx of Held's axon to follow repetitive firing with high precision and fidelity.

\section{Discussion}

Direct presynaptic terminal recordings from the calyx of Held in LES rats revealed that myelin loss reduces AP timing fidelity and reliability. We found that central dysmyelination affects not only AP spike velocity, but importantly for the auditory system, also the exact presynaptic spike timing and reliability. The LES rat axons that terminate as calyces of Held thus provide an elegant model system for understanding the pathophysiological effects of reduced compact myelin in the CNS.

\section{Myelination renders axons and nerve terminals capable of reliable high-frequency firing with high temporal precision} Previous characterization of LES rats showed that there is no condensed myelin in the CNS (Kwiecien et al., 1998; Smith et al., 2013). Accordingly, our immunohistochemistry analysis shows that the LES rat MNTB does not stain with MBP antibody (Fig. $1 E$ ). Myelination is important for the clustering of $\mathrm{Na}_{\mathrm{v}} 1.6$ channels at nodes of Ranvier during development, and for the rapid, reliable, and efficient propagation of action potentials along axons (Vabnick and Shrager, 1998). Dysmyelination is known to increase the expression of ectopic $\mathrm{Na}$ and $\mathrm{K}$ channels on axons (Waxman et al., 2004; Sinha et al., 2006). This may greatly decrease their input resistance of the internode membrane, which together with an increase in membrane capacitance will greatly slow the speed of the AP. LES axons exhibit improper localization of internodal (Kv1.1, 1.2 channels) and paranodal proteins (e.g., Caspr) in spinal cord axons (Eftekharpour et al., 2005). This may lead to decreased amplitudes and increased spike latency in extracellular field recordings in LES rats, although these previous studies did not report an increased jitter in spike timing (Eftekharpour et al., 2005). The shiverer mouse, a homolog of the LES rat, also has axons with a dispersed distribution of $\mathrm{K}^{+}$channels along the internodes (both Kv1.1 and Kv12; Sinha et al., 2006) and retarded Na-channel clustering, which result in immature field potentials and increased AP latencies (Rasband et al., 1999; Bando et al., 2008).

P16-P18 LES calyces showed a threefold slower AP propagation velocity than normal calyces, and LES calyces had almost a fourfold decrease in presynaptic spike timing precision (i.e., increased jitter) compared with myelinated calyces at $10 \mathrm{~Hz}$ stimulation (Fig. 2). We suggest that this increased spike timing variability in the LES calyces may be linked to the slower AP conduction speed in the mutant $L E S$ afferent fibers.

\section{Myelin loss affects the exact AP waveform at nerve terminals}

Axons undergo a sequence of excitability changes after the conduction of a nerve impulse, related to after-potentials following an AP spike; the ADP and AHP (Bostock and Rothwell, 1997). In addition to the refractory period, axonal ADP and AHP determine superexcitability or subexcitability of motor axons (Bostock et al., 2005). In the auditory system, the exact timing of spikes is used to encode sound intensity and pitch. Thus, the ADP and AHP at auditory axons may modulate neuronal entrainment by sound. The mature calyx of Held exhibits a fast AHP, and after the AP spike an ADP characterized by a fast upstroke phase and a slower decay phase (Kim et al., 2010). Our results show that the fast AHP and ADP are both affected by myelin loss in the LES rats (Fig. 3). Previous studies have shown that active resurgent $\mathrm{Na}^{+}$ currents or $\mathrm{K}^{+}$currents affect the amplitude of the ADP (Dodson et al., 2003; Kim et al., 2010), and passive discharge currents regulate the decay phase of the ADP (Borst et al., 1995). At the calyx of Held, tetraethylammonium (TEA)-sensitive Kv3 channels contribute to shorter AP waveforms and more reliable spiking at high frequencies (Wang et al., 1998; Nakamura and Takahashi, 2007). In particular, the TEA-sensitive Kv3 channel and $\mathrm{Na} 1.6$ channels, which increase in density during development, underlie the presynaptic fAHP and ADP, respectively, in the calyx of Held (Kim et al., 2010). We thus suggest that the number of active $\mathrm{Na}^{+}$channels is reduced in LES axons because the ADP is reduced in size. In addition, the AP trains showed more failures during high-frequency stimulation (e.g., $300 \mathrm{~Hz}$ or $1 \mathrm{kHz}$; Fig. 4) in the mutant LES rats, which may also be caused by reduced $\mathrm{Na}^{+}$channel densities. Accordingly, treatment of axons with low doses of tetrodotoxin leads to more AP failures during high-frequency trains (Madeja, 2000).

\section{Hearing disorders and dysmyelination of auditory afferent fibers}

Symptoms of multiple sclerosis (MS) can include loss of hearing acuity (Noffsinger et al., 1972). In cases with hearing loss, $85 \%$ show sensorineural bilateral high-frequency loss (Peyvandi et al., 2010). This typical symptom of hearing loss in MS is similar to those shown in auditory neuropathy (Starr et al., 2000; Rance, 2005). Recent studies have suggested that auditory neuropathy is closely related to disrupted neuronal synchrony, resulting perhaps from impaired hair cell ribbon synapses, myelin damage, or a reduction in the number of functioning fibers (Oertel, 2005; Rance, 2005). Here, we examined the effect of myelin loss specifically on AP firing at the single axon and nerve terminal level in the mammalian auditory brainstem. Our results suggest that abnormalities in timing of AP firing due to dysmyelination may lead to problems in understanding speech for some auditory neuropathy patients (Zeng et al., 2005).

In conclusion, our results show that myelination reduces spike jitter, promoting the precise encoding of the timing of sound signals in the ascending auditory system. The fast propagation velocities of APs in myelinated axons make them better suited to transmit spike timing information than unmyelinated axons, because fast conduction speeds minimize the conduction delay of spikes over long distances (Wang et al., 2008). The evolution of myelination in vertebrate animals thus provided major advantages: more precise spike timing and greater dynamic range of spike rate encoding to convey sensory and motor information across long distances in the CNS, with minimal use of metabolic energy and with reduced jitter.

\section{References}

Bando Y, Takakusaki K, Ito S, Terayama R, Kashiwayanagi M, Yoshida S (2008) Differential changes in axonal conduction following CNS demyelination in two mouse models. Eur J Neurosci 28:1731-1742. CrossRef Medline

Barrett EF, Barrett JN (1982) Intracellular recording from vertebrate myelinated axons: mechanism of the depolarizing afterpotential. J Physiol 323:117-144. Medline

Borst JG, Helmchen F, Sakmann B (1995) Pre- and postsynaptic whole-cell recordings in the medial nucleus of the trapezoid body of the rat. J Physiol 489:825-840. Medline

Bostock H, Rothwell JC (1997) Latent addition in motor and sensory fibres of human peripheral nerve. J Physiol 498:277-294. Medline

Bostock H, Lin CS, Howells J, Trevillion L, Jankelowitz S, Burke D (2005) After-effects of near-threshold stimulation in single human motor axons. J Physiol 564:931-940. CrossRef Medline

Carr CE, Soares D, Parameshwaran S, Perney T (2001) Evolution and development of time coding systems. Curr Opin Neurobiol 11:727-733. CrossRef Medline 
Delaney KH, Kwiecien JM, Wegiel J, Wisniewski HM, Percy DH, Fletch AL (1995) Familial dysmyelination in a Long Evans rat mutant. Lab Anim Sci 45:547-553. Medline

Dodson PD, Billups B, Rusznák Z, Szûcs G, Barker MC, Forsythe ID (2003) Presynaptic rat Kv1.2 channels suppress synaptic terminal hyperexcitability following action potential invasion. J Physiol 550:27-33. CrossRef Medline

Eftekharpour E, Karimi-Abdolrezaee S, Sinha K, Velumian AA, Kwiecien JM, Fehlings MG (2005) Structural and functional alterations of spinal cord axons in adult Long Evans Shaker (LES) dysmyelinated rats. Exp Neurol 193:334-349. CrossRef Medline

Kim JH, Kushmerick C, von Gersdorff H (2010) Presynaptic resurgent $\mathrm{Na}^{+}$ currents sculpt the action potential waveform and increase firing reliability at a CNS nerve terminal. J Neurosci 30:15479-15490. CrossRef Medline

Kwiecien JM, O'Connor LT, Goetz BD, Delaney KH, Fletch AL, Duncan ID (1998) Morphological and morphometric studies of the dysmyelinating mutant, the Long Evans shaker rat. J Neurocytol 27:581-591. CrossRef Medline

Leão RM, Kushmerick C, Pinaud R, Renden R, Li GL, Taschenberger H, Spirou G, Levinson SR, von Gersdorff H (2005) Presynaptic Na + channels: locus, development, and recovery from inactivation at a high-fidelity synapse. J Neurosci 25:3724-3738. CrossRef Medline

Madeja M (2000) Do neurons have a reserve of sodium channels for the generation of action potentials? A study on acutely isolated CA1 neurons from the guinea-pig hippocampus. Eur J Neurosci 12:1-7. CrossRef Medline

Nakamura Y, Takahashi T (2007) Developmental changes in potassium currents at the rat calyx of Held presynaptic terminal. J Physiol 581:1101-1112. CrossRef Medline

Noffsinger D, Olsen WO, Carhart R, Hart CW, Sahgal V (1972) Auditory and vestibular aberrations in multiple sclerosis. Acta Otolaryngol [Suppl 303]:1-63. Medline

O'Connor LT, Goetz BD, Kwiecien JM, Delaney KH, Fletch AL, Duncan ID (1999) Insertion of a retrotransposon in Mbp disrupts mRNA splicing and myelination in a new mutant rat. J Neurosci 19:3404-3413. Medline

Oertel D (2005) Importance of timing for understanding speech. J Neurophysiol 93:3044-3045. CrossRef Medline

Paradiso K, Wu LG (2009) Small voltage changes at nerve terminals travel up axons to affect action potential initiation. Nat Neurosci 12:541-543. CrossRef Medline

Peyvandi A, Naghibzadeh B, Ahmady Roozbahany N (2010) Neurootologic manifestations of multiple sclerosis. Arch Iran Med 13:188-192. Medline

Rance G (2005) Auditory neuropathy/dys-synchrony and its perceptual consequences. Trends Amplif 9:1-43. CrossRef Medline

Rasband MN, Peles E, Trimmer JS, Levinson SR, Lux SE, Shrager P (1999) Dependence of nodal sodium channel clustering on paranodal axoglial contact in the developing CNS. J Neurosci 19:7516-7528. Medline

Seidl AH, Rubel EW, Harris DM (2010) Mechanisms for adjusting interaural time differences to achieve binaural coincidence detection. J Neurosci 30:70-80. CrossRef Medline

Sinha K, Karimi-Abdolrezaee S, Velumian AA, Fehlings MG (2006) Functional changes in genetically dysmyelinated spinal cord axons of shiverer mice: role of juxtaparanodal Kv1 family $\mathrm{K}^{+}$channels. J Neurophysiol 95:1683-1695. CrossRef Medline

Smith CM, Cooksey E, Duncan ID (2013) Myelin loss does not lead to axonal degeneration in a long-lived model of chronic demyelination. J Neurosci 33:2718-2727. CrossRef Medline

Starr A, Sininger YS, Pratt H (2000) The varieties of auditory neuropathy. J Basic Clin Physiol Pharmacol 11:215-230. Medline

Taschenberger H, von Gersdorff H (2000) Fine-tuning an auditory synapse for speed and fidelity: developmental changes in presynaptic waveform, EPSC kinetics, and synaptic plasticity. J Neurosci 20:9162-9173. Medline

Vabnick I, Shrager P (1998) Ion channel redistribution and function during development of the myelinated axon. J Neurobiol 37:80-96. CrossRef Medline

Wang LY, Gan L, Forsythe ID, Kaczmarek LK (1998) Contribution of the Kv3.1potassium channel to high-frequency firing in mouse auditory neurones. J Physiol 509:183-194. CrossRef Medline

Wang SS, Shultz JR, Burish MJ, Harrison KH, Hof PR, Towns LC, Wagers MW, Wyatt KD (2008) Functional trade-offs in white matter axonal scaling. J Neurosci 28:4047-4056. CrossRef Medline

Waxman SG, Craner MJ, Black JA (2004) $\mathrm{Na}^{+}$channel expression along axons in multiple sclerosis and its models. Trends in Pharmacological Sciences 25:584-591. CrossRef Medline

Zeng FG, Kong YY, Michalewski HJ, Starr A (2005) Perceptual consequences of disrupted auditory nerve activity. J Neurophysiol 93:30503063. CrossRef Medline 